\title{
GIST of Mesocolon: A Case Report
}

\author{
Malla S', Rawal SB' ${ }^{1}$, Giri NK ${ }^{1}$ \\ Department of Surgery, Shree Birendra Hospital
}

\begin{abstract}
Gatrointestinal Stromal Tumor (GIST) is a rare soft tissue tumor and a GIST arising from the mesocolon is even rarer and sparsely reported in the world literature. Herein we report one such case that we encountered in our clinical practice and review the literature on the management of such a rare case.
\end{abstract}

Key words: Gatrointestinal Stromal Tumor, Mesocolon, Soft tissue tumor

\section{Introduction}

Gatrointestinal Stromal Tumors (GIST) is a rare soft tissue tumor representing $0.2 \%$ of all gastrointestinal tumors. GIST arising from the mesocolon is even rarer and is usually diagnosed only after histopathological study of resected specimen.

\section{Case Report}

A 54 year old lady hailing from Pokhara, presented to the Surgical Out Patient Department with complaints of a gradually progressive abdominal lump in the left loin, of one year duration. The lump was initially small, barely noticeable to start with, but had grown in prominence for the last 2 months. She gave no history of altered bowel habits, weight loss or features of $\mathrm{Gl}$ bleeding. On examination, her general condition was fair and abdominal examination revealed a firm to hard mass 12 $X 13 \times 10 \mathrm{~cm}$ located on her left lower quadrant. The mass was mildly tender, had irregular surface and was mobile. Digital rectal examination was normal.

The patient was further investigated with the provisional diagnosis of Colonic malignancy. Her stool report was 'positive' for occult blood. Ultrasonography of abdomen revealed a mixed echoic Space Occupying Lesion 10.6 × $10.3 \mathrm{cms}$ in left lumbar region, likely to be a colonic Carcinoma. Barium enema was however normal up to left lateral third of transverse colon. Hence a CECT Scan was performed which revealed a large heterogenous enhancing soft tissue mass $9.3 \times 8.1 \mathrm{x}$ $10.7 \mathrm{~cm}$, extending from lower border of left kidney up to the left iliac crest pushing descending colon posterolaterally and small bowel loops anteriorly.

With the probable diagnosis of soft tissue sarcoma or a GIST, exploratory laparotomy was performed. The per operative findings was of a $12 \times 8 \times 8 \mathrm{cms}$ mass arising from sigmoid mesocolon adherent to wall of sigmoid colon, transverse colon and proximal jejunum. Subsequently, a limited left hemicolectomy from midtransverse colon to sigmoid colon was performed together with the excision of $45 \mathrm{~cm}$ jejunum adherent to mass, approximately $15 \mathrm{~cm}$ from Duodeno-Jejunal junction.

The patient made an uneventful post operative recovery and was discharged on the tenth post operative day. The Histopathological report revealed a Gastrointestinal Stromal tumour (GIST) of sigmoid mesentry with ulceration of intestinal mucosa by the tumour and margins free of tumor. Moderate cellularity with mitotic figures of 3 per $50 \mathrm{HPF}$ was reported. Subsequently immunohistochemistry was sent and was reported to be CD- 117 Positive, thus confirming the diagnosis of GIST.

\footnotetext{
Address for Correspondence:

Name: Dr. Srijan Malla

E-mail: srijan@email.com

Ph. No.: 9851064964
} 


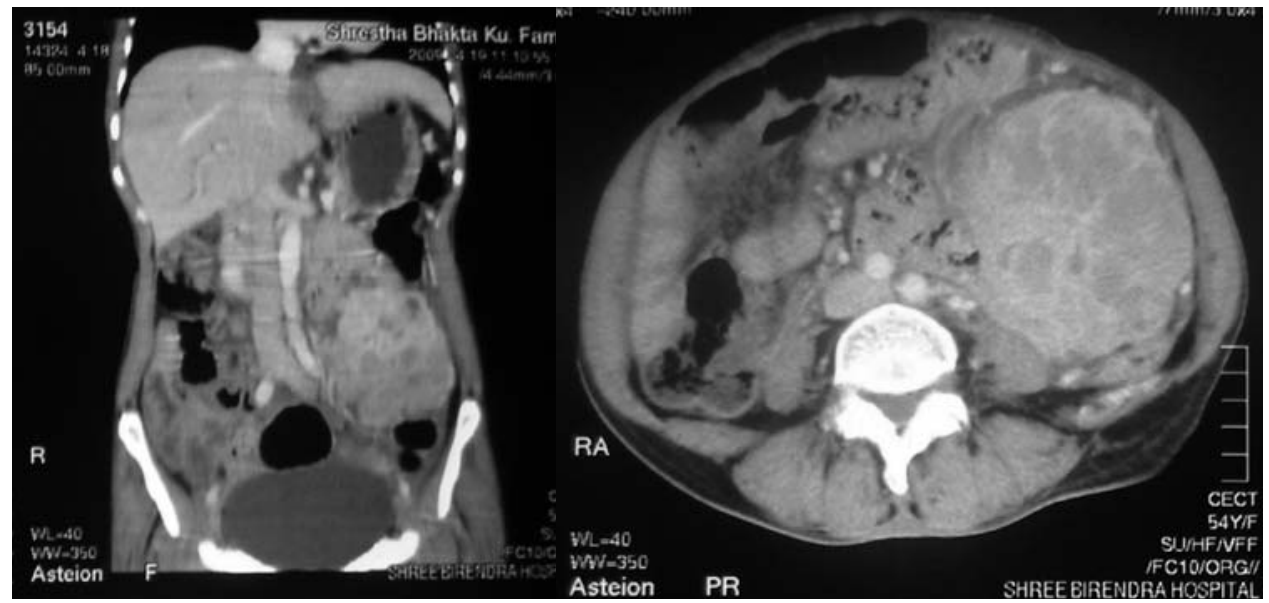

Fig 1: CECT abdomen showing heterogenous mass It lumbar region

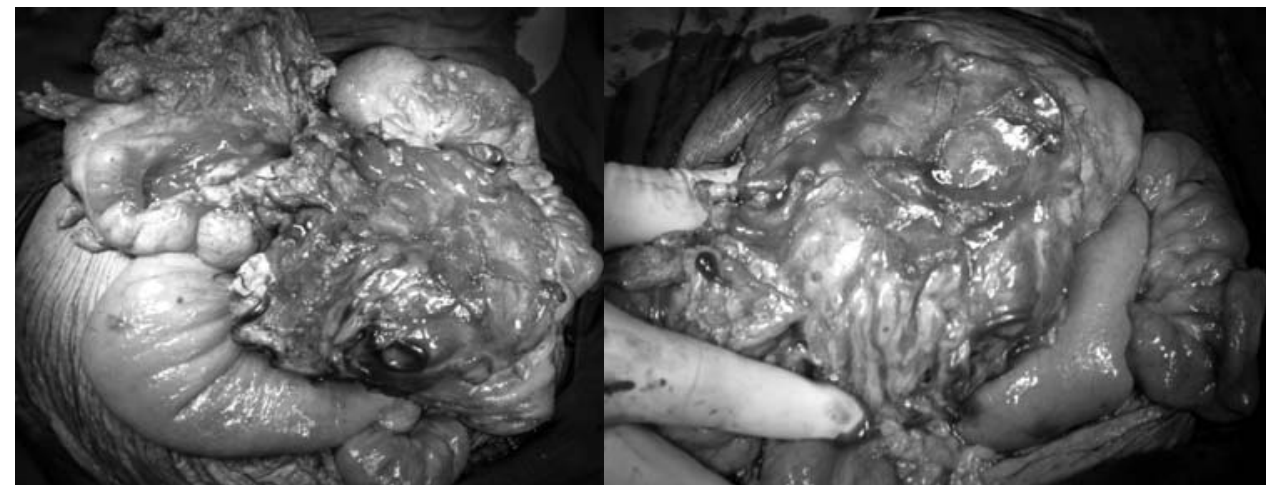

Fig 2: Mass arising from Sigmoid mesocolon adherent to jejunum

\section{Discussion}

Sarcoma of the gastrointestinal tract arises from stromal cells of the intestinal wall. The vast majority of these tumors possess myogenic features, and historically they have been classified as leiomyosarcoma ${ }^{1}$. After the advent of immunostaining and electron microscopy, however, some gastrointestinal sarcomas were found to exhibit both myogenic and neurogenic features ${ }^{2,3}$. Accordingly, the term "gastrointestinal stromal tumor (GIST)" was adopted, in $1983^{4}$. It has recently been proposed that this tumor arises from the interstitial cells Cajal. GISTs are rare soft tissue tumors representing $0.2 \%$ of all gastrointestinal tumors. The predominant sites for GISTs are stomach in $50-60 \%$, small intestine$30-40 \%$, colon \& rectum- $5-10 \%$, oesophagus- $5 \%$. They are rarely found in the omentum, mesentery or the retroperitoneum. Of the reported omental and mesenteric GISTs in four published series a total of 99 such tumors were studied ${ }^{5,6,7,8}$. Further, only two case reports of GIST arising in the mesocolon were found in the literature ${ }^{9,10}$.
The symptoms and signs of GISTs are nonspecific depending, to some extent, on their size, site, and pattern of growth. In contrast to intramural GIST, mesenteric and omental tumors can grow to a large size without causing symptoms.

The histologic diagnosis is confirmed in fewer than half of the patients prior to the time of surgery. A CT-guided biopsy is not always done because intraabdominal tumor-cell seeding can compromise future resectability, and patients with a ruptured tumor have a prognosis similar to that in patients with noncurative resection. Percutaneous needle biopsy should only be performed when the tumor is clearly unresectable or when an alternative diagnosis such as lymphoma or germ-cell tumor is suspected.

There is little agreement about the treatment and prognosis of lymph-node metastasis from GIST. Because such metastasis is considered an infrequent 
event in the natural history of these tumors, local excision has a rational basis and elective lymphadenectomy is generally not indicated ${ }^{13}$.

The overall survival rate for patients with a GIST is $28 \%-35 \%$ at 5 years, and the rate increases to $54 \%$ $65 \%$ after complete resection. ${ }^{14}$ Patients with a lowgrade rectal GIST have a significantly longer median survival than those with a high-grade tumor (median survival, 5-10 years versus 2-3 years). Mitotic activity, cellularity and presence of necrosis have been found to be associated with worse outcomes. Reith et al found a mitotic rate of $>2 / 50 \mathrm{HPF}$, the presence of necrosis, and high cellularity to be useful in predicting biologic behavior in GISTs, which tend to have an aggressive behavior $^{8}$.

Complete gross surgical resection with negative microscopic margins remains the mainstay treatment of localised resectable GIST. Currently; trials are underway to establish the role of adjuvant and neoadjuvant therapy for high risk cases. Advanced, nonresectable and/or metastatic GIST is safely and continuously treated with imatinib at $400 \mathrm{mg}$ daily.

\section{Conclusion}

GIST of mesocolon is a rare tumor whose mainstay of treatment remains complete $\mathrm{RO}$ surgical resection. The use of adjuvant therapy with imatinib is still based on the clinical judgment of the treating physician in the absence of results of ongoing clinical trials.

\section{References}

1. Akwari OE, Dozois RR, Weiland LH, Beahrs $\mathrm{OH}$. Leiomyosarcoma of the small and large bowel. Cancer 1978; 42:1375-84.

2. Lauwers GY, Erlandson RA, Casper ES, Brennan MF, Woodruff JM. Gastrointestinal autonomic nerve tumors:Aclinicopathological, immunohistochemical, and ultrastructural study of 12 cases. Am J Surg Pathol 1993; 17:887-97.

3. Erlandson RA, Klimstra DS, Woodruff JM. Subclassification of gastrointestinal stromal tumors based on evaluation by electron microscopy and immunohistochemistry. Ultrastruct Pathol 1996; 20:373-93.
4. Mazur MT, Clark HB. Gastric stromal tumors: Reappraisal of histogenesis. Am J Surg Pathol 1983; 7:507-19.

5. Miettinen M, et al. Gastrointestinal stromal tumors/ smooth muscle tumors (GISTs) primary in the omentum and mesentery: clinicopathologic and immunohistochemical study of 26 cases. Am J Surg Pathol 1999, 23:1109-1118.

6. Sakurai S, et al. Gastrointestinal stromal tumors and KIT-positive mesenchymal cells in the omentum. Pathol Int 2001, 51:524-531.

7. Yamamoto $\mathrm{H}$, et al. c-kit and PDG-FRA mutations in extragastrointestinal stromal tumor (gastrointestinal stromal tumor of the soft tissue). Am J Surg Pathol 2004, 28:479-488.

8. Reith JD, Goldblum JR, Lyles RH, Weiss SW. Extragastrointestinal (soft tissue) stromal tumors: an analysis of 48 cases with emphasis on histologic predictors of outcome. Mod Pathol 2000, 13:577585.

9. Paparelli $\mathrm{C}$ et al. Giant GIST of the mesocolon: report of a case. Minerva Chir. 2006 Dec; 61(6): 537-40.

10. Jacobs K, de Gheldere Ch, Vanclooster P. A ruptured gastrointestinal stromal tumour of the transverse mesocolon: a case report. Acta Chir Belg. 2006 Mar-Apr;106(2):218-21.

11. Fong Y, Coit DG, Woodruff JM, Brennan MF. Lymph node metastasis from soft tissue sarcoma in adults. Ann Surg 1993; 217:72-7.

12. DeMatteo RP et al. Two hundred gastrointestinal tumors: Recurrence patterns and prognostic factors for survival. Ann Surg 2000; 231:51-8.

13. Demetri GD, et al. NCCN Task Force report: management of patients with gastrointestinal stromal tumor (GIST) - update of the NCCN clinical practice guidelines. J Natl Compr Canc Netw. 2007;5(Suppl 2):S1-29;quiz S30.

14. Montemurro $M$, et al. Diagnosis and treatment of GIST in Switzerland. [Guidelines]. SchweizMed Forum. 2008; 8(30-31):544-9. 